\title{
El Teatro en el Aula de Clases
}

\author{
Theater in the Classroom
}

DOI: $10.46932 / \mathrm{sfjdv} 2 \mathrm{n} 2-029$

Received in: january 1st, 2020

Accepted in: March 30th, 2020

\section{Susana María Soledad Espinosa Ramírez}

Magíster en Literatura Infantil y Juvenil. Diplomado en Pedagogía. Profesora fiscal (durante 25 años), coordinadora institucional de alfabetización, capacitadora de docentes de literatura en EDINUN y profesora a tiempo completo de la UTPL.

Correspondencia: smespinoza@utpl.edu.ec

\section{Amelia Isadora Rodríguez Fernández}

Magíster en Educación a Distancia e Ingeniera en Ecoturismo. Ha sido profesora en la Universidad Nacional de Loja - UNL (por ocho años) y docente investigadora del CEDAMAZ (por un año). Actualmente, se desarrolla como docente universitaria en la UTPL.

Correspondencia: airodriguez1@utpl.edu.ec

\section{Nancy Cecilia Hidalgo Puchaicela}

Psicóloga Clínica, Licenciada en Ciencias de la Educación (mención Educación Básica), Diplomado en Psicología Clínica y Forense y Magíster en Gestión y Desarrollo Social. Fue, docente investigadora en la UTPL. Presta sus servicios en la Fiscalía General del Estado (Loja), directora Fundación Sociocultural Don Bosco y psicoterapeuta integrativa de libre ejercicio.

Correspondencia: nchidalgo@utpl.edu.ec

\section{Adrián Felipe Vásquez Escandón}

Magíster en Psicoterapia Integrativa. Fue perito acreditado del Ministerio Público y de la Función Judicial del Azuay así como docente universitario en la Universidad del Azuay - UDA. Actualmente, se desarrolla como docente universitario en la UTPL/UNL, psicoterapeuta de la Fundación Sociocultural

Don Bosco y psicoterapeuta integrativo de libre ejercicio.

Correspondencia: afvasquez@utpl.edu.ec / adrian.vasquez@unl.edu.ec

\section{RESUMEN}

El innovar el aula es una responsabilidad del docente, por esta razón se planteó como propuesta emplear el teatro como herramienta didáctica, lo que se efectuó en ocho paralelos durante el ciclo académico octubre 2016- febrero 2017 y se demostró que se puede combinar el arte con la enseñanza, la belleza con el aprendizaje y la innovación con los contenidos planificados. Cada docente empleó una estrategia diversa en su aula de clases, basadas en el teatro; y, se coincidió en la conformación de equipos de trabajo para la obtención de productos de aprendizaje, a través de la ilustración, el diálogo y el drama, resaltan: radio teatro, infografías, memes, puestas en escena, microvideos, cortometrajes, libretos, entre otros. Además, la utilización del material reciclable, producto de los refrigerios que se compartieron, fue un valor agregado porque se crearon diversos objetos como parte de la conciencia ecológica, consecuencia que trae consigo la sensibilización que se adquiere con este arte. Se adaptó, adecuó y diseñó los contenidos aprendidos en cada componente en material creación de los alumnos: ideas, lenguaje, propia expresión e inconfundible vitalidad, sirvieron para demostrar su dominio científico. Por tanto, el teatro es una herramienta importante que une, desarrolla el trabajo en equipo, fortalece el liderazgo, motiva la 
producción literaria, sensibiliza, crea conciencia y cambia de actitud ante los problemas sociales, dando a ellos una respuesta positiva.

Palabras Claves: ambiente, aprendizaje, creatividad, drama, teatro, comunidad.

\section{INTRODUCCIÓN}

En este proyecto vamos a demostrar que el teatro en el aula de clases puede ser una herramienta útil de expresión oral, escrita y corporal que se puede usar para trabajar contenidos de diversas asignaturas.

Mediante el teatro, los estudiantes pueden descubrir aquellas habilidades y competencias que normalmente no son admiradas por sí mismos, luego al desarrollar esta actividad ingresan a un mundo nuevo que les permite: mejorar sus relaciones interpersonales, desarrollar su creatividad y analizar la realidad existente, dando una respuesta innovadora a los problemas sociales, dentro de su comunidad.

El objetivo fue desarrollar una herramienta pedagógica basada en el teatro para la formación de los estudiantes universitarios, siendo necesario motivarlos a la lectura de obras literarias y la observación de videos alusivos a la realidad abordada, con la respectiva interpretación; promoviendo con ello, en forma transversal: la práctica de normas, principios y valores así como la difusión de la memoria colectiva.

Las metas trazadas se cumplieron plenamente y los productos obtenidos son Recursos Educativos Abiertos [REA] con política Creative Commons o la puesta en escena (utilizando la dramatización) de sus propias producciones, cuya selección ha sido colgada un portal web, canal YouTube y cta. Twitter, que fueron creadas para el efecto, haciendo uso de las Tecnologías de la Información y la Comunicación [TIC].

Para evidenciar los resultados obtenidos se aplicó una encuesta que arroja como resultado tanto la satisfacción por la práctica realizada como la demostración de los conocimientos aprendidos en el desarrollo del ciclo o semestre.

\section{EL TEATRO EN EL AULA DE CLASES}

El teatro ayuda a la formación integral de los estudiantes, en sus tres dimensiones: saber ser, actuar y hacer, dentro de cada una se descubren las competencias genéricas y específicas de cada componente académico o asignatura.

\subsection{ANTECEDENTES}

El teatro es uno de los lenguajes artísticos del hombre, nace en el marco de festividades religiosas griegas y fue la base para el teatro romano. Aristóteles sentó las bases conceptuales en su Poética (siglo IV a.C.), de la cual varios de sus preceptos se mantienen hasta la actualidad.

Según esta concepción inicial, el teatro era básicamente didáctico y debía suplir el deseo de aprender del público, si bien es cierto esta función puede ser muy importante, y de hecho mediante nuestro 
proyecto la estamos retomando, también hay que considerar que ha evolucionado de muchas maneras y ahora se habla de: "teatro de los sentidos", "teatro mudo", "teatro documental", "teatro del oprimido" o "teatro de sombras", cuyo fin puede incluir la diversión, el cuestionamiento social e incluso el cambio de comportamiento.

\subsection{DIFERENCIA ENTRE DRAMATIZACIÓN Y TEATRO}

De acuerdo a varios argumentos citados por Onieva (2011), en su estudio de "dramatización como recurso educativo..." se indica que hay una diferencia entre la dramatización y el teatro, resaltan:

La dramatización es aquella actividad que utiliza la herramienta teatral en una práctica lúdica, orientada hacia sí misma y sin proyección exterior. Es un conjunto de prácticas al servicio de la expresión creadora del individuo y el desarrollo integral de su personalidad (Tejerina, 2004; p.118). ... La dramatización es un instrumento pedagógico que fomenta y potencia en sus participantes valores (Ferrer et al., 2003), habilidades sociales (Guil y Navarro, 2005), así como diferentes medios de expresión, orales y escritos (Motos, 1992)...

... Según Jerez (2004), el teatro supone una vivificación del texto, es hacer presente un discurso activo a través del cuerpo y la voz. El objetivo es la representación teatral, la puesta en escena de textos dirigidos a un público, y que suele estar acompañado de otras artes como las escenografías escénicas, de maquillaje e iluminación... (Onieva, 2011, p. 76-118).

\subsection{EL TEATRO DENTRO DE LA SALA DE CLASES}

Dentro de esta gama de posibilidades que vimos, el uso del teatro dentro de la sala de clases no es nuevo, ya que es una forma de expresión que le permite al docente enseñar a sus estudiantes maneras de solucionar problemas de diversa índole, pues se pueden abordar distintos temas que al ser representados, se pueden mirar desde diversas ópticas, analizarlos, entenderlos y modificarlos.

De acuerdo a Laferriére (2004) el arte dramático está considerado como una asignatura y a la vez es una herramienta pedagógica que facilita la enseñanza de otras materias curriculares pues:

\footnotetext{
Cuando se reúnen las posibilidades pedagógicas que ofrece con los objetivos de la educación social, se produce una dinámica bastante interesante que permite a los enseñantes aprovechar una multitud de ocasiones para hacer un teatro vivo y una enseñanza activa y participativa; porque el teatro tiene mucho en común con los objetivos de la educación social” (p.62).

El teatro, el arte dramático y la pedagogía de la expresión son herramientas educativas básicas para la intervención en el campo de la formación. Y para las personas en dificultad de inserción social suponen encontrar salidas para formar parte de la sociedad." (p. 63).
}

Esta estrategia de enseñanza - aprendizaje ha sido reconocida y validada en diferentes latitudes, incluido Ecuador, un ejemplo de ello es la Universidad Nacional de la Loja [UNL], que en el currículo, dentro de la descripción del plan de estudios de la Carrera de Lengua Castellana y Literatura (2012), señala como cátedra: "Teatro y Expresión Corporal” y, de la misma manera, Universidad de las Américas [UDLA], con existe la materia: "Expresión Corporal y Dramática”. Adicionalmente, hay diversas 
publicaciones sobre este tema, entre otros el documento: Fear and Shame: Using Theatre to Destigmatise Mental Illness in an Australian Macedonian Community (Blignault, et al. 2010), según el cual se logró mediante la representación de una obra teatral la visualización, aceptación y tolerancia hacia personas con enfermedades mentales para poder luego implementar acciones de ayuda y mejora; y, el artículo: The Theater and Pedagogy in the History of Education (Sánchez, 2015), publicación que relata la experiencia de los jesuitas al incorporar el teatro en el currículo de escuelas y la representación de dramas con elementos religiosos y profanos contemporáneos con fines didácticos, logrando gran éxito en esta labor.

\subsection{CARACTERÍSTICAS DEL TEATRO}

Según Sormani (2004) que cita a Dubatti (s.f.) señala que el teatro tiene tres características que le hacen diferente del cine, televisión, literatura, la plástica y la música, pues es el acontecimiento que nos permite: a) un intercambio humano directo, rechaza lo tecnológico que implica separación de la interacción humana; b) un lenguaje o poético, orden en la expresión oral o corporal (mímica, escenario, iluminación, sonidos, vestuario); y, c) un acontecimiento de constitución del espacio del espectador, transmisión del mensaje, creación de conciencia.

"El teatro en el aula... dispone ojos donde hay ceguera, abre una brecha donde había un muro, actúa como sangría más que como emplasto, contiene el dolor que no tiene cura, otorga garganta abierta a los mudos. Es milagroso, puede llegar a hacernos oír aquello para lo cual éramos sordos" (De la Parra, citado por Sornami, 2004, p. 59).

\subsection{FORMAS DE HACER TEATRO}

Existen tres formas básicas de hacer teatro en el aula de clases: 1) lectura participativa (que atrae al estudiante y se entusiasma al leer en alta voz, se comparte con sus compañeros, puede variar los tonos de voz, para atraer); 2) escenificación (trata de simular con vestuario y escenario algún tema que se desea representar para tener una mayor claridad); y, 3) compañía teatrales (apreciar obras de teatro de forma directa o videos, previa selección del docente -se recomienda que exista un diálogo posterior sobre la obra entre los artistas y alumnos). Lo que actúa como un eje integral de la formación del ser humano, que está abierto a todo tipo de público, motiva la unidad familiar, el rescate de valores (espirituales, culturales y morales), actúa como medio de aprendizaje y fomenta la lectura, creatividad y producción.

\subsection{NUESTRAS EXPERIENCIAS DEL TEATRO EN EL AULA DE CLASES}

A un $92,9 \%$ de los estudiantes les ha gustado participar del proyecto; un $46,2 \%$ prefieren especialmente temas sobre problemas sociales y entretenimiento; un 47,4\% reconoce que el hacer teatro le aportó en mejorar la comunicación oral, escrita y corporal como el control emocional para hablar ante el público; un 78,6\% sugiere que el teatro debería impartirse como parte de la educación desde la escuela; 
y, un 50\% considera existe un balance entre el teatro y la clase magistral, siendo el primero mejor que lo segundo, en razón de: mejorar el aprendizaje, ser lectura comentada, facilitar el trabajo grupal y aprender en forma amena.

\section{CONCLUSIONES}

El teatro en el aula de clases es una magnífica herramienta didáctica, que adquiere mayor trascendencia porque es elaborado por los estudiantes, quienes lo adecuan a su medio con su propia terminología, ejemplos y relaciones, lo que hace que los contenidos de las asignaturas sean más cercanos, accesibles y propios. Sumado a que lo disfrutan e ingenian sin límites (fuera de convencionalismos), y trabajan con los contenidos de la asignatura, practican valores.

Los participantes conocen, comprenden y valoran el género teatral dentro de una sociedad y como parte de su cultura en general. El teatro propicia la actividad lúdica, es decir, el uso divertido y creativo del tiempo y el buen gusto por la literatura y artes.

Al realizar REA sus autores sienten satisfacción del trabajo hecho y salen enriquecidos en su autodominio, autoestima y autorrealización personal. A lo que se suma la utilización de las inteligencias múltiples, la aplicación de principios del constructivismo y la mejora continua de la expresión oral y escrita. 


\section{REFERENCIAS}

\section{Libros:}

[1] N. Sornami, "El teatro para niños". Del texto al escenario. Incluye obras de Ana Alvarado y Patricia Suárez, Colección Leer y Escribir, Ediciones Homo Sapiens, Argentina, 2005, pp. 1-50.

\section{Tesis:}

[2] J. Onieva, "La dramatización como un recurso educativo: Estudio comparativo de una experiencia con estudiantes malagueños de un centro escolar concertado y adolescentes puertorriqueños en situación de marginalidad", Tesis doctoral, Departamento de Didáctica de la Lengua y Literatura, Universidad de Málaga, Málaga, 2011.

Artículos:

[3] Blignault, I., Smith, S., Woodland, L., Ponzio, V., Ristevski, D., Kirov, S. (2010). Fear and Shame: Using theatre to destigmatise mental illness in an Australian Macedonian community. Health Promotion Journal of Australia, 21 (2), 120-126 ISSN: 10361073

[4] Laferriére, Georges. (2014). Decano de la Facultad de Arte, Universidad Québec á Montréal La pedagogía teatral, una herramienta para educar. Educación Social núm. 13 pp. 54-65.

[5] Sánchez, V.C. (2.015). The theater and pedagogy in the history of education. Tonos Digital. 28(1), 74. ISSN: 15776921. 